\title{
A FEMINILIDADE COMO UMA POSIÇÃO DE SUJEITO:
}

\author{
UMAABORDAGEM LACANIANA
}

\author{
Bruno Alves Coelho
}

Resumo: O objetivo do presente trabalho é diferenciar duas formas de pensar a feminilidade. A primeira, entendida a partir da economia libidinal de um homem e a segunda como uma forma própria de um sujeito se constituir sexuado. Neste trabalho, a feminilidade é pensada como uma posição do sujeito, e buscamos aproximar alguns dos principais conceitos que Freud e Lacan usam para pensar a feminilidade, nomeadamente, no caso de Freud, no que diz respeito à configuração particular da libido feminina entre a libido objetal e a libido narcísica e, no caso de Lacan, no que diz respeito à relação da mulher com o falo ser mediada por uma forma diferente de relação com o Outro.

Palavras-chave: Feminilidade. Masculinidade. Sexuação. Psicanálise. Diferença sexual.

O objetivo do presente trabalho é diferenciar duas formas de pensar a feminilidade. A primeira, dizendo resumidamente, entendida a partir da economia libidinal de um homem e a segunda, enquanto uma forma própria de um sujeito se constituir sexuado.

Para introduzir o tema, é importante lembrar que a diferença sexual para a psicanálise, desde Freud, não se reduz à diferença sexual do ponto de vista anatômico. Freud (1933/1976) diz explicitamente que "aquilo que constitui a masculinidade ou a feminilidade é uma característica desconhecida que foge ao alcance da anatomia" (p. 141). 
A seguir, Freud tece uma crítica sobre a definição da diferença sexual dentro da psicanálise como o estabelecimento de padrões de comportamento que valeriam para cada um dos sexos. Podemos encontrar aqui inclusive uma breve crítica à relação inequívoca que ele tinha proposto alguns anos antes entre atividade/masculino e passividade/feminino e à noção de bissexualidade constitutiva da sexualidade humana que daí deriva. Segue o trecho:

Estamos habituados a empregar "masculino" e "feminino" também como qualidades mentais, e da mesma forma temos transferido a noção de bissexualidade para a vida mental. Assim, dizemos que uma pessoa, seja homem ou mulher, se comporta de maneira masculina em uma situação e feminina, em outra. Os senhores, porém, logo percebem que isso é ceder à anatomia ou às convenções.... Quanto mais se afastarem da esfera sexual, mais óbvio se Ihes tornará o erro de superposição. As mulheres podem demonstrar grande atividade, em diversos sentidos; os homens não conseguem viver em companhia dos de sua própria espécie, a menos que desenvolvam uma grande dose de adaptabilidade passiva. Se agora os senhores me disserem que esses fatos provam justamente que tanto os homens como as mulheres são bissexuais, no sentido psicológico, concluirei que decidiram na sua mente fazer coincidir ativo com masculino e passivo com feminino. Mas advirto-os que não o façam. Parece-me que não serve a nenhum propósito útil e nada acrescenta a nossos conhecimentos. (Freud, 1933/1976, pp. 141-143)

A partir desses pontos fundamentais escolhemos começar o nosso estudo da feminilidade pensando a mulher na economia libidinal de um homem. Para tanto julgamos útil retomarmos a proposição de Freud (1910/1970) a respeito de uma cisão na vida amorosa dos homens entre o objeto de desejo sexual e o objeto de amor. Ele desenvolve que o objeto de amor remete ao primeiro momento mítico da relação do menino com a mãe antes do Édipo e que o objeto do desejo sexual remete ao desejo da mãe nomeado pela identificação com o pai no Édipo. Em 1912, Freud (1912/1970) fala de uma tendência masculina de sempre, em certa medida, separar o objeto de amor do objeto de desejo, o que resulta frequentemente em um certo nível de inibição da sexualidade em relação a uma mulher por quem ele está apaixonado, ou complementarmente, em uma tendência nos homens a só conseguirem alcançar a sua potência sexual máxima através de um objeto sexual depreciado, um objeto que mantém certa distância em relação ao objeto que poderia ser eleito a partir da identificação do menino com o pai no Édipo. É importante ter em mente aqui que o objeto de investimento amoroso, apesar de ter relação com o objeto eleito a partir da identificação com o pai no Édipo, não é a mesma coisa que esse objeto, mesmo que, para um homem, uma mesma pessoa possa ser alvo tanto de amor quanto de atração sexual. 
Para clarificar esse ponto julgamos importante recuperar o que Lacan (1960/1998a) chama à nossa atenção sobre o caráter inconsciente a partir do qual o desejo opera:

Pois aí se vê que a insciência que o homem tem de seu desejo é menos insciência daquilo que ele demanda - que, afinal, pode ser cingido - do que insciência a partir da qual ele deseja. (p. 829)

Mas para podermos desdobrar melhor as explicações sobre essa tendência, que Freud nomeou de tendência à degradação do objeto de investimento libidinal na vida erótica masculina, e nos aprofundarmos na compreensão da relação que um homem mantém com o objeto do seu desejo, torna-se preciso pensar a masculinidade não só a partir dos registros do amor e do desejo, mas também a partir do registro da pulsão.

Para começarmos a pensar a maneira específica a partir da qual a masculinidade se reflete no nível pulsional, cabe termos em mente o que Freud (1905/1989) nos trouxe sobre uma grande afinidade da masculinidade com o que ele descreveu como ideal de organização genital da libido; nesse ideal, as tendências pré e pós-edípicas caminhariam juntas em um único objeto centralizador da libido que aqui ele denomina de genital. Freud (1914/2006) fala também de uma grande afinidade entre a masculinidade e o que ele nomeou de libido objetal.

Mas para avançarmos sobre esse assunto seria interessante retomarmos uma comparação que Freud propõe a respeito da diferença radical entre a forma como a pulsão opera e a relação de um beberrão com o vinho:

Consideremos, por exemplo, a relação de um beberrão com o vinho. Não é verdade que o vinho sempre proporciona ao beberrão a mesma satisfação tóxica que, na poesia, tem sido tão frequentemente comparada à satisfação erótica - uma comparação que também é igualmente aceitável do ponto de vista científico? Alguém já ouviu falar de que o beberrão seja obrigado a trocar constantemente de bebida, porque logo enjoa de beber a mesma coisa? Ao contrário, o hábito constantemente reforça o vínculo que prende o homem à espécie de vinho que ele bebe. Alguém já ouviu falar de um beberrão que precise ir a um país em que o vinho seja mais caro ou em que seja proibido beber, de modo que, erguendo obstáculos, ele possa aumentar a satisfação decrescente que obtém? De maneira nenhuma. Se atentarmos para o que dizem os grandes alcoólatras, como Böcklin, a respeito de sua relação com o vinho, ela aparece como a mais harmoniosa possível, um modelo de casamento feliz. Por que a relação do amante com seu objeto sexual será tão profundamente diferente? Por mais estranho que pareça, creio que devemos levar em consideração a possibilidade de que algo semelhante na natureza do próprio instinto sexual é desfavorável à realização da satisfação completa. (Freud, 1912/1970, p. 171)

PSICologia USP, São Paulo, 2013, 24(1), 99-117. 
O que é importante notar nessa passagem é a ideia de que a libido objetal também carrega traços de uma relação não linear com o seu objeto, apesar de nem por isso ser correto fazer o conceito de pulsão equivaler-se ao de desejo. Para melhor compreendermos essa distinção entre pulsão e desejo cabe retomarmos Lacan (1960/1998a) quando ele diz que "o desejo do homem é o desejo do Outro" (p. 829). Há muito a ser dito sobre esse aforismo, mas o nosso objetivo ao trazê-lo aqui é chamar a atenção para a estruturação eminentemente simbólica do desejo no ser humano. É possível ler esse aforismo também a partir da ideia de que o alvo último do desejo no ser humano é a sua própria formulação, que falha, e tem por efeito o desejo continuar operando ao nível inconsciente. No mesmo texto, Lacan (1960/1998a) traz uma definição bastante concisa e útil de pulsão que pode nos ajudar a entender essa distinção melhor:

[a pulsão] é o que advém da demanda quando o sujeito aí se desvanece. Que a demanda também desaparece é evidente, exceto que resta o corte, pois este continua presente no que distingue a pulsão da função orgânica que ela habita: ou seja, seu artifício gramatical, muito patente nas reversões de sua articulação com a fonte e o objeto (Freud quanto a isso é inesgotável). (p. 831)

Alguns pontos aqui merecem a nossa atenção. O primeiro é a distinção entre a pulsão e algo que pudesse ser nomeado como instinto, ou algum tipo de natureza orgânica que já não fosse modificada pela sua relação com a linguagem. A segunda questão fundamental é o que ele chama de um esvanecimento do sujeito nesse nível. Cabe lembrar que o sujeito é, antes de qualquer coisa, sujeito do significante e que se o autor confere à pulsão um caráter asubjetivo podemos ler essa passagem como indicando que o ciclo de repetição autônoma da pulsão não é capturado pela rede significante no limite da qual o sujeito pode ser pensado. O terceiro ponto é a explicação para esse caráter não linear que a pulsão adquire. Podemos ler nesse trecho a ideia de que, para Lacan, essa circulação da pulsão em torno do seu objeto é uma marca que ela carrega do significante (artifício gramatical), e uma testemunha de que a pulsão não é simplesmente independente da rede simbólica no limite da qual um sujeito pode ser pensado, mas que ela emerge como resultado desse recorte que um sujeito faz do real ao se constituir como desejante.

Zizek (1999) trabalha esse mesmo ponto de uma maneira bastante interessante no trecho a seguir:

O que não se pode perder de vista é o fato de que, para Lacan, a pulsão não é algo "primordial", uma base a partir da qual, através da intervenção da lei simbólica, o desejo emerge. Uma leitura atenta do 'gráfico do desejo' de Lacan mostra como a pulsão é uma montagem de elementos que emergem como um tipo de "subproduto necessário" do corpo instintual ser capturado pela ordem 
simbólica. (p. 296, tradução nossa)

Essas precisões todas se tornam necessárias para não reduzirmos o lugar que uma mulher poderia ocupar na economia libidinal de um homem à função de fazer desejar, ou de máscara da castração na dialética do desejo, uma vez que uma mulher também entra em jogo para um homem de uma forma diferente enquanto objeto de amor e objeto de gozo, o que por si só já problematiza a leitura de Freud proposta, por exemplo, por Khel, (2008) quando ela afirma que:

Freud ouviu a crise entre as mulheres e a feminilidade e entendeu que a cura de suas histéricas equivalia a remetê-las de volta a esta mesma feminilidade da qual elas já se desajustavam, em função da própria multiplicidade de discursos e possibilidades de escolha surgidas na modernidade. Assim, se produz que: para a psicanálise, feminilidade acaba sendo equivalente a histeria, e há uma valorização da mulher histérica como aquela que sabe manejar a mascarada da feminilidade e colocar-se na posição feminina frente ao homem. (p. 265)

Mas o nosso objetivo com esse trabalho não é só pensar a mulher na economia libidinal masculina, mas também pensarmos a mulher em uma posição de sujeito, e para tanto seguiremos agora alguns pontos chave das contribuições de Freud a esse respeito.

Um primeiro ponto crucial é lembrarmo-nos da importância que Freud atribui à relação pré-edípica da menina com a mãe. Podemos ver a seguir que, para ele, essa relação primordial com a mãe é que vai formar as bases a partir das quais a relação com o pai no Édipo, e com os homens posteriormente, vão se estruturar:

Sabíamos, naturalmente, que houvera um estádio preliminar de vinculação com a mãe, mas não sabíamos que pudesse ser tão rico e tão duradouro, e pudesse deixar atrás de si tantas oportunidades para fixações e disposições. Durante essa fase, o pai da menina é apenas um rival incômodo; em alguns casos, a vinculação à mãe perdura além do quarto ano de vida. Quase tudo o que posteriormente encontramos em sua relação com o pai, já estava presente em sua vinculação inicial e foi transferido, subseqüentemente, para seu pai, Em suma, fica-nos a impressão de que não conseguimos entender as mulheres, a menos que valorizemos essa fase de sua vinculação pré-edipiana à mãe. (Freud, 1933/1976, pp. 147-148)

Torna-se aqui, então, necessário explorarmos com maiores detalhes essa primeira relação libidinal da menina com a mãe para, então, voltarmos a isso que Freud chamou de transferência das influências da ligação pré-edípica da menina com a mãe para a fase de ligação ao pai no Édipo. Um ponto interessante para começarmos é notar que, nesse período de 
ligação libidinal com a mãe, o ego da menina ainda está em processo de formação, chegando a se consolidar somente em um período posterior junto à constituição do ideal do eu no Édipo:

O desenvolvimento do ego consiste num afastamento do narcisismo primário e dá margem a uma vigorosa tentativa de recuperação desse estado. Esse afastamento é ocasionado pelo deslocamento da libido em direção a um ideal do ego imposto de fora, sendo a satisfação provocada pela realização desse ideal. (Freud, 1914/2006, p. 106)

Voltaremos à questão da importância do estado ainda não consolidado do ego nesse período a seguir na nossa discussão do Édipo feminino. Por ora, cabe destacar que a consolidação do ideal do eu também é o critério que Freud usou para marcar a passagem do narcisismo primário para o que ele chamou de ideal masculino de organização genital da libido. Disso concluímos que a relação pré-edípica da menina com a mãe corresponde ao que Freud descreveu em 1914 como o período do narcisismo primário.

Uma imagem interessante que Freud usa para esclarecer o conceito de libido narcísica é a de uma massa de libido original que emitiria pseudópodes, que ele identifica com o investimento de libido objetal, a fim de se locomover:

É difícil dizer algo do comportamento da libido no id e no superego. Tudo o que sabemos sobre ela relaciona-se com o ego, no qual, a princípio, toda a cota disponível de libido é armazenada. Chamamos a este estado absoluto de narcisismo primário. Ele perdura até o ego começar a catexizar as idéias dos objetos com a libido, a transformar a libido narcísica em libido objetal. Durante toda a vida, o ego permanece sendo o grande reservatório, do qual as catexias libidinais são enviadas aos objetos e para o qual elas são também mais uma vez recolhidas, exatamente como uma ameba se conduz com os seus pseudópodos. É somente quando uma pessoa se acha completamente apaixonada que a cota principal de libido é transferida para o objeto e este, até certo ponto, toma o lugar do ego.... Não se pode discutir que a libido tenha fontes somáticas, que ela flua para o ego de diversos órgãos e partes do corpo. Isto se vê mais claramente no caso daquela porção da libido que, por seu objetivo instintivo, é descrita como excitação sexual. As partes mais proeminentes do corpo de que esta libido se origina são conhecidas pelo nome de "zonas erógenas", embora, de fato, o corpo inteiro seja uma zona erógena desse tipo. (Freud, 1940[1938]/1975, p. 176)

Alguns detalhes aqui merecem uma atenção especial no nosso percurso de pensar a posição de sujeito de uma mulher a partir dos textos de Freud, como o uso da expressão "zonas erógenas" no plural, sem sugerir a sua confluência em uma zona erógena única e a marcação de manei- 
ra explícita de que a libido objetal só pode substituir em parte a libido narcísica, nunca equivaler totalmente a ela. Encontramos, aqui, marcada uma cisão fundamental entre a libido objetal e a libido narcísica, sem a sugestão de uma tentativa de confluência das duas em um ideal de organização genital da libido.

A partir disso escolhemos retomar com mais detalhes o conceito de libido narcísica com que Freud trabalha. Na passagem acima, podemos notar que é a partir do ego que Freud procura representar o conceito de libido narcísica, um ego não totalmente consolidado como lembramos um pouco antes. Tendo isso em vista resolvemos retomar duas passagens importantes em que Freud trata do ego antes de prosseguirmos na nossa compreensão da libido narcísica:

O ego é, primeiro e acima de tudo, um ego corporal; não é simplesmente uma entidade de superfície, mas é, ele próprio, a projeção de uma superfície. (Freud, 1923/1976, p. 40)

Assim, em sua relação com o id, ele é como um cavaleiro que tem de manter controlada a força superior do cavalo, com a diferença de que o cavaleiro tenta fazê-lo com a sua própria força, enquanto que o ego utiliza forças tomadas de empréstimo. (Freud, 1923/1976, p. 39)

É tendo em mente a importância do corpo no conceito de libido narcísica que lemos o que Freud (1914) traz sobre a escolha objetal da mulher ser de natureza narcísica, em contraste com a escolha objetal masculina que ele denomina de uma ligação objetal completa, o que quer dizer que a escolha objetal feminina é marcada pela lógica presente nesse período que Freud denominou de narcisismo primário e por uma erotização desse ato psíquico que implica o alcance do que o ego pode realizar em relação ao que existe em estado de potencialidade no id, uma vez que nesse período já existe um ego em construção.

A fim de clarificar a concepção de id que entra em jogo no conceito de narcisismo primário, retomamos Freud (1914/2006) mais uma vez quando ele admite que começa a pensar o conceito de libido narcísica a partir de uma base biológica, enquanto um ponto de referência altamente abstrato que ligaria o sujeito à totalidade da sua espécie, enquanto algo que precede o sujeito e que subsiste a ele e em relação a que ele se constitui:

O indivíduo leva realmente uma existência dúplice: uma para servir as suas próprias finalidades e a outra como um elo numa corrente, que ele serve contra sua vontade ou pelo menos involuntariamente. $\mathrm{O}$ indivíduo considera a sexualidade como um dos seus próprios fins, ao passo que, de outro ponto de vista, ele é um apêndice de seu germoplasma, a cuja disposição põe suas energias em troca de uma retribuição de prazer. Ele é o veículo mortal de uma 
substância (possivelmente) imortal - como o herdeiro de uma propriedade inalienável, que é o único dono temporário de um patrimônio que lhe sobrevive. A separação dos instintos sexuais dos instintos do ego simplesmente refletiria essa função dúplice do indivíduo. (Freud, 1914/2006, pp. 85-86)

O primeiro ponto a ser notado é que a referência de Freud à biologia não é algo que permanece da mesma forma durante toda a sua obra, uma indicação de como ele gradativamente se afasta de uma explicação biologicista e passa a considerar a importância da cultura, e de como o corpo pode ser ressignificado, pode ser encontrada na direção que segue a primeira citação deste trabalho, que diz respeito a um texto posterior de Freud. O segundo ponto a ser notado é o eco dessa noção de narcisismo com o conceito de Outro barrado em Lacan como a rede simbólica dentro da qual um sujeito nasce e se constitui e do Outro postulado como absoluto enquanto um ponto de referência a partir do qual não houvesse limites em relação ao que poderia ser articulado simbolicamente. Que Lacan tenha explicitado a inconsistência de alguma forma de absoluto desse tipo não impediu que ele levasse em conta a importância que um certo tipo de referência a esse absoluto desempenha na vida erótica feminina, e nem fez com que ele subtraísse a importância do corpo nesse conceito e o pensasse somente a partir do ponto de vista da linguagem. Nesse sentido, a distinção entre libido objetal e libido narcísica não diz respeito a tomar a si mesmo ou a alguma outra coisa como objeto, mas como duas lógicas distintas de escolha objetal. Da mesma forma se encontra descartada a leitura da sexualidade feminina como algo fora da cultura, mas como uma forma bastante específica de inserção no mundo da cultura pelo édipo, como desenvolveremos mais a seguir com Lacan.

Mas retornando a Freud não podemos deixar de tentar trabalhar a questão de por que, em última instância, existe a necessidade da ligação da libido a objetos e por que não é possível uma concretização sem mediação desse referencial absoluto de que vínhamos falando, tal como essa concretização é suposta nesse primeiro período mítico de ligação da criança com a mãe. Freud (1914/2006) trabalha essa questão no trecho a seguir:

Nesse ponto, nossa curiosidade naturalmente perguntará por que esse represamento da libido no ego teria de ser experimentado como desagradável. Contentar-me-ei com a reposta de que o desprazer é sempre a expressão de um grau mais elevado de tensão, e que, portanto, o que ocorre é que uma quantidade no campo dos acontecimentos materiais é transformada, aqui como em outros lugares, na qualidade psíquica do desprazer. Não obstante, talvez o fator decisivo para a geração do desprazer não seja a magnitude absoluta do acontecimento material, mas antes alguma função específica dessa magnitude absoluta. Aqui podemos até mesmo aventurar-nos a abordar a questão de saber o que torna absolutamente necessário para a nossa vida mental ultrapassar os 
limites do narcisismo e ligar a libido a objetos. A resposta decorrente de nossa linha de raciocínio mais uma vez seria a de que essa necessidade surge quando a catexia do ego com a libido excede certa quantidade. Um egoísmo forte constitui uma proteção contra o adoecer, mas, num último recurso, devemos começar a amar a fim de não adoecermos, e estamos destinados a cair doentes se, em conseqüência da frustração, formos incapazes de amar. Isso acompanha mais ou menos os versos do quadro que Heine traça sobre a psicogênese da Criação. (pp. 91-92)

Nesse sentido, nas palavras de Freud, o ato de amar, ou o investimento libidinal de objetos, altera a função específica da magnitude absoluta dos acontecimentos de ordem material que possam provocar desprazer. Assim, amar é o resultado da impossibilidade de efetivar diretamente esse estado de narcisismo primário devido aos eventos de natureza material que se lhe interpõem, o ato de investir a libido em objetos altera a função e a importância da magnitude absoluta de um evento material que possa vir a representar a impossibilidade de efetivar sem nenhum tipo de mediação o estado de narcisismo primário, e permite que ele seja postulado de uma outra forma mais abrangente, mediado dessa vez já por um tipo de relação com o falo. O início já de um tipo de relação com o falo é o que marca a distinção do período denominado por Freud de Narcisismo Primário do período anterior por ele denominado de autoerotismo.

Tendo isso em mente, se retomarmos a característica incompleta do ego como característica do narcisismo primário e sua ligação com a projeção de uma superfície corporal podemos tentar lançar uma compreensão sobre o que Freud descreve no Édipo sobre as queixas da menina contra a mãe que marcam o período de transição para o pai como objeto de investimento afetivo. Podemos ver isso com Freud no trecho a seguir:

Orientaremos, agora, nosso interesse no sentido de saber unicamente que coisa põe fim a essa poderosa vinculação da menina à sua mãe. Conforme sabemos, este é o seu destino habitual: está determinado a dar lugar a uma vinculação a seu pai.... Esse passo no desenvolvimento não envolve apenas uma simples troca de objeto. $\mathrm{O}$ afastar-se da mãe, na menina, é um passo que se acompanha de hostilidade; a vinculação à mãe termina em ódio. Um ódio dessa espécie pode tornar-se muito influente e durar toda a vida; pode ser muito cuidadosamente supercompensado, posteriormente; geralmente, uma parte dele é superada, ao passo que a parte restante persiste.... Muitas dentre elas [acusações e queixas contra a mãe] são evidentes racionalizações e as verdadeiras origens da hostilidade restam por ser encontradas. (Freud, 1933/1976, p. 150)

Nesse processo cabe destacar o caráter de descontinuidade corporal que marca as queixas da menina em relação à mãe, e a função da mag- 
nitude absoluta da inveja do pênis no processo de entrada da menina no Édipo. O pênis ganha importância aqui como suporte das teorias sexuais infantis na tentativa da criança de nomear o desejo da mãe para além de si própria. E a questão sobre o desejo da mãe surge de um sentimento pela menina de não correspondência da sua demanda de amor pela mãe. O movimento em direção ao pai surge na medida em que surge na menina a suposição de que os impasses da sua relação com a mãe poderiam encontrar resposta através da ligação com o pai, uma vez que é para o ele, ou para quem desempenha a sua função, que o desejo da mãe se dirige. Esse primeiro tipo de investimento objetal que permanece marcado por esse referencial de um absoluto impossível é o que caracteriza a relação da menina com o falo, que pode ser compreendida por hora usando a mesma metáfora usada por Freud da libido narcísica que se movimenta frente aos seus impasses através da emissão de pseudópodes, de modo que a forma de a referência a esse absoluto poder manter alguma consistência é através de uma relação parcial com ele, que Freud conceptualiza a partir da ideia de uma relação mediada por um ego não totalmente consolidado, e que Lacan conceptualiza a partir da lógica de uma relação não toda com o falo. A ideia de que esse referencial absoluto é algo que se movimenta também é um ponto fundamental no nosso entendimento do conceito de libido narcísica em Freud, uma vez que a possibilidade desse tipo de movimento é incompatível com uma interpretação puramente biológica desse conceito.

Essa configuração particular da libido feminina é o que define a posição subjetiva da mulher, e ela não pode ser inferida se partirmos da modalidade masculina de investimento objetal. Nesse sentido não importa quão alto nos colocarmos o valor desse objeto que pode ser pensado a partir da forma masculina de organização da libido, pensar a feminilidade somente a partir desse lugar ainda é um preço insuficiente a se pagar para a psicanálise se isentar de pensar a feminilidade como constitutiva de uma posição de sujeito.

Nesse sentido, podemos avançar para a escolha por Freud (1931/1974) de definir a forma de investimento libidinal feminina como narcísica. Não se trata aqui de dizer que a mulher ama a sua imagem especular no objeto de seu amor nem que ela tende a amar alguém na medida em que essa pessoa reforce pura e simplesmente a sua auto-imagem ou algo parecido. Trata-se aqui de uma outra forma a partir da qual um sujeito pode advir como sexuado quando ele destaca a importância que pode desempenhar na sexualidade feminina essa forma de investimento libidinal característica do período que ele denominou de narcisismo primário.

A partir disso podemos finalmente trazer para o primeiro plano a afirmação de Freud (1925/1976) de que a castração inibe a masculinidade e incentiva a feminilidade: 
Enquanto, nos meninos, o complexo de Édipo é destruído pelo complexo de castração, nas meninas ele se faz possível e é introduzido através do complexo de castração. Essa contradição se esclarece se refletirmos que o complexo de castração sempre opera no sentido implícito em seu conteúdo: ele inibe e limita a masculinidade e incentiva a feminilidade. (p.318)

A fim de desdobrar melhor como a castração funciona de uma forma diferente em relação à masculinidade e à feminilidade será necessário nos reportarmos ao que Lacan (1972-1973/1985) desenvolve no seminário 20 sobre as formulas da sexuação:

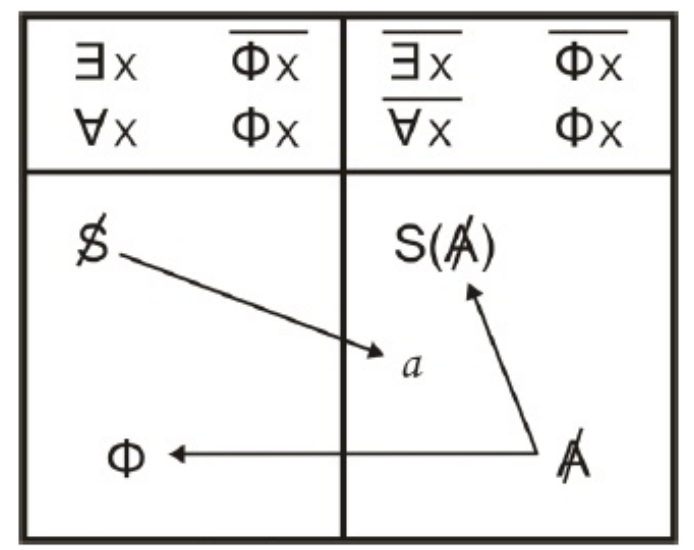

Figura: Recuperado de Lacan (1972-1973/1985, p. 105)

O lado esquerdo do gráfico é o lado que representa a lógica masculina de relação com o falo. A lógica da universalidade da função fálica ( $\mathbf{V x}$ Фx) fundada por uma exceção $\mathbf{H x} \overline{\Phi \mathbf{x}}$ tal como Lacan (1972-1973/1985) desenvolve no trecho que segue:

Primeiro, as quatro fórmulas proposicionais, em cima, duas a esquerda e duas a direita. Quem quer que seja ser falante se inscreve de um lado ou de outro. Á esquerda $\mathbf{V} \mathbf{x}_{\Phi x}$ indica que é pela função fálica que o homem como todo toma inscrição, exceto que essa função encontra o seu limite em um $x$ pelo qual a função $\Phi x$ é negada, $\mathbf{H} \mathbf{x} \overline{\Phi \mathbf{x}}$. Aí está o que chamamos de função do pai - de onde procede pela negação a função $\overline{\Phi \mathbf{x}}$, o que funda o exercício do que supre, pela castração, a relação sexual - no que esta não é de nenhum modo inscritível. O todo repousa portanto, aqui, na exceção colocada, como termo, sobre aquilo que esse $\Phi x$ nega integralmente. (p. 107)

O que gostaríamos de destacar nessa passagem é que o ponto de partida dessa lógica é a castração e, como podemos ver na parte de baixo 
do gráfico, a constituição do objeto $a$ como aquilo com que um homem fundamentalmente tem relação. Esse objeto é a exceção que sustenta a função fálica como representante daquilo que não pode ser incluído nessa função. Esse procedimento é capaz de fundar um todo, e de centralizar de certa forma a libido de um homem com relação a esse objeto, mas com a condição de que esse objeto no centro esteja ausente. Ele é a exceção que funda a função fálica e ao mesmo tempo o elemento que resiste à integração a ela. Enfim, podemos dizer que o que está em jogo aqui é que o sujeito masculino (\$) se define por uma divisão em relação a um significante que pudesse representá-lo em relação a todos os outros significantes a partir da reintegração desse excesso que é o objeto $a$.

O ponto surpreendente é que para Lacan o ponto de partida para a mulher não é a castração ou a divisão subjetiva frente um significante que teria de reintegrar um excesso e centralizar a libido. $O$ ponto de partida é o Outro e a divisão de que se parte na mulher como sujeito é a divisão no Outro (A), em relação à qual a castração desempenha um papel secundário.Trouxemos duas passagens de Lacan para justificar esse ponto:

Da próxima vez tentarei enunciar de maneira que se sustente - e que seja bem completa para que vocês o possam suportar pelo tempo que durará em seguida a retomada, quer dizer, meio mês - que do lado da mulher - mas marquem esse $a$ com o traço oblíquo com que designo o que se deve barrar - do lado de A mulher, é de outra coisa que não do objeto $a$ que se trata no que vem em suplência a essa relação sexual que não há. (Lacan, 1972-1973/1985, p. 86)

Por essa razão, a elucubração Freudiana sobre o complexo de Édipo, que faz da mulher peixe na água, pela castração ser nela ponto de partida (Freud dixit), contrasta dolorosamente com a realidade de devastação que constitui, com a mulher, em sua maioria, a relação com a mãe, de quem, como mulher, ela parece esperar mais substância que do pai - o que não combina com ele ser segundo nessa devastação. (Lacan, 1973/2003a , p. 465)

Nesse sentido a partir de Lacan é possível afirmar que nem mesmo a castração poderia desempenhar o papel de formar uma equação entre os sexos, e é nesse sentido que lemos o aforismo que aparece na primeira citação sobre não haver relação sexual, nesse sentido o que há entre os sexos não é algo da ordem de uma equação, e é preciso supor dois sujeitos que vão se arranjar frente aos encontros e desencontros que o contato entre eles pode vir a provocar. E a partir da importância fundamental de pensarmos esse outro ponto de partida para podermos pensar a feminilidade como uma posição de sujeito que iremos agora a mais uma passagem em que Lacan pode nos ajudar a esclarecer essa questão: 
Quanto a nós, partiremos do que a sigla $\mathrm{S}(\mathrm{A})$ articula, por ser antes de tudo um significante. Nossa definição do significante (não existe outra) é:um significante é aquilo que representa o sujeito para outro significante. Esse significante, portanto, será aquele para o qual todos os outros significantes representam o sujeito: ou seja, na falta desse significante, todos os demais não representariam nada. Já que nada é representado senão para algo. (Lacan, 1960/1998a, p. 183)

O que gostaríamos de destacar nesse trecho são as duas formas de se pensar o sujeito que nele aparecem. A primeira a partir da fórmula "um significante é o que representa um sujeito para outro significante", ou o sujeito é o que é representado por um significante frente a todos os outros, na medida em que ele serve ou não como para nomear esse excesso que é o objeto $a$. Para a fórmula "significante... em relação ao qual todos os outros significantes representam o sujeito" Aqui são todos os outros significantes (sem exceção) que representam o sujeito frente a um significante. O nosso ponto aqui é enfatizar que localizando o Outro enquanto barrado como ponto de partida se cria uma outra forma a partir da qual um sujeito pode ser pensado no nível da enunciação. O que tem como efeito entre outras coisas que Lacan tenha escolhido o matema $A$ para escrever a mulher enquanto sujeito no gráfico abaixo das fórmulas da sexuação, e não o matema \$.

Enfim, localizar a feminilidade no nível da enunciação também é uma forma de distanciarmos nossa leitura da leitura que localizaria a muIher fora da linguagem, ou mais fora da linguagem que o homem. Seguimos Copjec (1994) nesse ponto na sua leitura da diferença sexual do ponto de vista da psicanálise como duas formas de pensar o limite interno da linguagem.

Mas para desenvolvermos melhor a forma pela qual é possível pensar os sujeitos que se alinham do lado direito das fórmulas de sexuação resolvemos retomar mais uma passagem em que Lacan trabalha essa questão de uma forma mais explícita:

Para se introduzir como metade a se dizer das mulheres o sujeito se determina a partir de que, não existindo suspensão na função fálica, tudo possa dizer-se dela, mesmo que provenha do sem razão. Mas trata-se de um todo fora de universo, que se lê de chofre a partir do quantificador como não todo.

O sujeito, na metade em que se determina pelos quantificadores negados, vem de que nada existente constitui um limite da função, que não pode certificar-se de coisa alguma que seja [da ordem] de um universo. Assim, por se fundarem nessa metade,"elas" são nãotodas o que tem também como consequência, e pela mesma razão que tampouco nenhuma delas é toda. (Lacan, 1973/2003a, p.466)

A forma que lemos a parte de cima do lado direito das fórmulas da sexuação é precisamente esse não haver suspensão na função fálica, não 
existe nenhum elemento nessa função que se trata de fundar que lhe serviria de exceção. É nesse ponto que localizamos a radicalidade da relação da mulher com o Outro. A parte de baixo do lado direito das fórmulas da sexuação lê-se como esse não todo da universalidade da função fálica, ou a partir da ideia de que a mulher também mantém uma relação particular com o falo, uma relação com o falo que é marcada pela sua relação com o Outro(A). Mas a fim de avançarmos mais nesse ponto da relação da mulher com o falo gostaríamos de retomar a frase de Lacan sobre a relação da mulher com a função fálica de que "tudo possa dizer-se dela, mesmo que provenha do sem razão" e ler isso a partir de uma aproximação da forma de funcionamento da sexualidade feminina e da psicose.

Freud já havia começado a falar disso na medida em que ele pensa a psicose a partir desse mesmo conceito de libido narcísica como podemos ver confirmado a seguir:

Tentarei aqui penetrar um pouco mais no mecanismo da parafrenia e reunirei os conceitos que já me pareçam merecedores de consideração. A diferença entre as afecções parafrênicas e as neuroses de transferência parecem-me estar na circunstância de que, nas primeiras, a libido liberada pela frustração não permanece ligada a objetos na fantasia, mas se retira para o ego (Freud, 1914/2006, p. 102).

Aqui Freud já adianta uma distinção entre as parafrenias e as neuroses a partir do emprego da libido objetal. Mas, enfim, enquanto tanto na feminilidade quanto na psicose é possível falar de uma importância fundamental da libido narcísica, no caso da psicose definitivamente não é possível dizer que a castração não funciona como limite uma vez que a definição mesma de psicose é a de uma estrutura psíquica que se funda a partir de um mecanismo de forclusão da castração. Lacan (1957-1958/1998b) nos esclarece melhor sobre a função da castração na psicose no trecho a seguir:

Para que a psicose se desencadeie, é preciso que o Nome-do-Pai, verworfen, foracluido, isto é, jamais advindo no lugar do Outro, seja ali invocado em oposição simbólica ao sujeito.

É a falta do Nome-do-Pai nesse lugar que, pelo furo que abre do significado, dá início à cascata de remanejamento do significante de onde provém o desastre crescente do imaginário, até que seja alcançado o nível em que significado e significante se estabilizam na metáfora delirante.

Mas como pode o Nome-do-pai ser chamado pelo sujeito no único lugar de onde poderia ter advindo e nunca esteve? Através de nada mais nada menos que um pai real, não forçosamente em absoluto, o pai do sujeito, mas Um-pai. (p.584) 
A fim de podermos esclarecer essa aproximação e distinção entre feminilidade e psicose decidimos retomar mais um momento em que Lacan (1973/2003b) se dedica especificamente a esse tema:

Assim, prosseguiremos a partir do Outro, do Outro radical evocado pela não relação que o sexo encarna - desde que aí se perceba que o Um só existe, talvez, pela experiência do (a)sexuado.

Para nós, ele tem tanto direito quanto o Um de fazer um axioma de sujeito.... É por isso que uma mulher - já que de mais de uma não se pode falar - uma mulher só encontra $O$ homem na psicose.

Postulemos esse axioma não porque $O$ homem não ex-sista como é o caso d' $A$ mulher, mas porque uma mulher o proíbe a si mesma, não por ele ser o Outro, mas porque "não há Outro do Outro", como costumo dizer.

Assim, o universal do que elas desejam é a loucura: todas as mulheres são loucas como se diz.É por isso mesmo que não são todas, isto é, não loucas de todo. (pp. 537-538)

A aproximação entre a feminilidade e a psicose se dá, portanto, por em ambos os casos se estabelecer uma relação com o que Lacan chama nesse trecho de o Outro radical que o sexo encarna, ou seja, em ambos os casos não haver suspensão na função fálica que serve como base para pensar o campo do Outro; no caso da feminilidade por não haver exceção à função fálica por ela ser fundada pela lógica do não todo à qual viemos nos referindo, que ainda constitui uma forma de investimento objetal, enquanto no caso da psicose pelo pai real ser chamado a intervir nesse lugar em que essa suspensão da função fálica viria a operar do lado esquerdo das fórmulas da sexuação, aqui de modo a fundar o Outro de forma absoluta, com todas as consequências que isso acarreta na sua amarração a partir do sintoma psicótico.

Mas, enfim, a título de conclusão poderíamos dizer que se em psicanálise se fala de um Édipo feminino é porque também é possível pensar a feminilidade como um destino, e que se formos sustentar a hipótese Freudiana da centralidade da importância da sexualidade no psiquismo humano é preciso pensar o sujeito da psicanálise como um sujeito sexuado. E se a psicanálise sustenta que as sexualidades masculina e feminina são fundamentalmente diferentes é possível chegar à conclusão de que a feminilidade também constitui uma posição de sujeito, que deve ser pensada de uma forma diferente da posição masculina, já que não é possível traçar uma equação entre as duas. 


\section{Femininity as a subject position: A Lacanian approach}

Abstract: The objective of this study is to distinguish between two ways of thinking about femininity by psychoanalysis. The first, understood from the point of view of the libidinal economy of a man, and the second as a definite way of a subject to constitute itself as a sexed being. In order to develop this idea of femininity as a subject position we tried to establish connections among some of the key concepts that Freud and Lacan used to think about this theme, specially, in the case of Freud, with regard to the particular configuration of female libido between object libido and narcissistic libido and, in the case of Lacan, with regard to woman's relationship to the phallus to be mediated by a different form of relationship with the Other..

Keywords: Femininity. Masculinity. Sexuation. Psychoanalysis. Sexual difference.

\section{La féminité comme une position de sujet: une approche lacanienne}

Résumé: Le but de cette étude est de faire la distinction entre deux manières de penser la féminité. La premiere est conçue a partir de l'économie libidinale d'un homme et la seconde comme une forme propre d'un sujet se constituer en tant que sexué. Afin de développer cette idée de la féminité comme une position de sujet, nous avons essayé de rapprocher des concepts clés que Freud et Lacan utilisent pour rendre compte de la thématique, à savoir entre ce que dit Freud à propos de la configuration particulière de la libido féminine entre la libido d'objet et la libido narcissique et ce que dit Lacan sur la relation de la femme avec le phallus comme étant médié par un autre rapport à l'Autre.

Mots-clés: Féminité. Masculinité. Sexuation. Psychanalyse. Différence sexuelle.

\section{La feminidad como una posición de sujeto: un enfoque lacaniano}

Resumen: El objetivo de este estudio consiste en distinguir entre dos formas de pensar la feminidad para el psicoanálisis. La primera, a partir de la economía libidinal de un hombre, y la segunda, en cuanto una forma propia de un sujeto de constituirse como sexual. El esfuerzo está en cómo tratar la idea de la feminidad como una posición de sujeto. Así, se trató establecer la conexión entre algunos de los conceptos clave que Freud y Lacan usan para dar cuenta del tema. Es decir, entre lo que Freud dice sobre la configuración particular de la libido femenina entre la libido objetal y la narcisista, y, lo que Lacan dice acerca de la relación de la mujer y del falo ser mediada por una forma de relación diferente con el Otro.

Palabras claves: Feminidad. Masculinidad. Sexuación. Psicoanálisis. Diferencia sexual. 


\section{Referências}

Copjec, J. (1994). Sex and the euthanasia of reason. In J. Copjec, Read my desire: Lacan against the historicists. England: The MIT Press.

Freud, S. (1970). Um tipo especial de escolha de objeto feita pelos homens (Contribuições à psicologia do amor I). In S. Freud, Edição standard das obras psicológicas completas de Sigmund Freud (J. Salomão, trad.,Vol. 11, pp. 147-157). Rio de Janeiro, RJ: Imago. (Trabalho original publicado em 1910)

Freud, S. (1970). Sobre a tendência universal à depreciação na esfera o amor (Contribuições à psicologia do amor II). In S. Freud, Edição standard das obras psicológicas completas de Sigmund Freud (J. Salomão, trad.,Vol. 11, pp. 159-173). Rio de Janeiro, RJ: Imago. (Trabalho original publicado em 1912)

Freud, S. (1974). Sexualidade feminina. In S. Freud, Edição standard das obras completas de Sigmund Freud (J. Salomão, trad.,Vol. 21, pp. 259-279). Rio de Janeiro, RJ: Imago. (Trabalho original publicado em 1931)

Freud, S. (1975). Esboço de psicanálise. In S. Freud, Edição standard das obras psicológicas completas de Sigmund Freud (J. Salomão, trad.,Vol. 23, pp. 165-329) Rio de Janeiro, RJ: Imago. (Trabalho original publicado em 1940 [1938])

Freud, S. (1976). O ego e o id. In S. Freud, Edição standard das obras completas de Sigmund Freud (J. Salomão, trad.,Vol. 19, pp. 32-41). Rio de Janeiro, RJ: Imago. (Trabalho original publicado em 1923)

Freud, S. (1976). Algumas conseqüências psíquicas da distinção anatômica entre os sexos. In S. Freud, Edição standard das obras completas de Sigmund Freud (J. Salomão, trad.,Vol. 19, pp. 309-320). Rio de Janeiro, RJ: Imago. (Trabalho original publicado em 1925)

Freud, S. (1976). Conferência XXXIII: feminilidade. In S. Freud, Edição standard das obras completas de Sigmund Freud (J. Salomão, trad.,Vol. 22, pp. 139-165). Rio de Janeiro, RJ: Imago. (Trabalho original publicado em 1933)

Freud, S. (1989). Três ensaios sobre a teoria da sexualidade. In S. Freud, Edição standard das obras completas de Sigmund Freud (J. Salomão, trad.,Vol. 7, pp. 118-230). Rio de Janeiro, RJ: Imago. (Trabalho original publicado em 1905)

Freud, S. (2006). Sobre o narcisismo: uma introdução. In S. Freud, Edição standard das obras psicológicas completas de Sigmund Freud (J. Salomão, trad.,Vol. 14, pp.81108). Rio de Janeiro, RJ: Imago. (Trabalho original publicado em 1914) 
Kehl, M. R. (2008). Deslocamentos do feminino (2a ed.). Rio de Janeiro, RJ: Imago.

Lacan, J. (1985). O seminário. Livro 20, Mais, ainda. Rio de Janeiro, RJ: Jorge Zahar. (Trabalho original publicado em 1972-1973)

Lacan, J. (1998a). Subversão do sujeito e dialética do desejo no inconsciente freudiano. In J. Lacan, Escritos (pp. 807-842). Rio de Janeiro: Jorge Zahar. (Trabalho original publicado em 1960)

Lacan, J. (1998b). De uma questão preliminar a todo o tratamento possível da psicose. In J. Lacan, Escritos (pp. 573-590). Rio de Janeiro, RJ: Jorge Zahar. (Trabalho original publicado em 1957-1958)

Lacan, J. (2003a). O aturdito. In J. Lacan, Outros escritos (pp. 448-497). Rio de Janeiro, RJ: Jorge Zahar. (Trabalho original publicado em 1973)

Lacan, J. (2003b). Televisão. In J. Lacan, Outros escritos (pp. 508-543). Rio de Janeiro, RJ: Jorge Zahar. (Trabalho original publicado em 1973)

Zizek, S. (1999). The ticklish subject: The absent centre of political ontology. New York, NY: Verso. 
Bruno Alves Coelho, psicólogo, Universidade Metodista de São Paulo. Endereço para correspondência: Rua Paraguai, 76, Jardim Panorama/Vila Fonseca, Ribeirão Pires, São Paulo, SP, Brasil.CEP 09401-270. Endereço eletrônico:bac_bruno@yahoo.com.br

Recebido: 23/07/2012

Aceito: 07/01/2013

Psicologia USP, São Paulo, 2013, 24(1), 99-117. 
